\title{
SOBRE TEORÍA LITERARIA Y HERMENÉUTICA BÍBLICA 1
}

\section{José Domínguez Caparrós}

\author{
Universidad Nacional de Educación a Distancia
}

Mis conocimientos de exégesis bíblica no pasan de los que pueda tener el curioso que se asoma tímidamente a un campo vecino y se extraña de que no se alimente su propia disciplina, la teoría literaria, con muchos de los frutos que allí se dan. Si la ciencia bíblica es filológica e histórica (Alonso Schökel, 1986: 27), llama mucho la atención que no se aprovechen, en los estudios literarios, los avances de la misma. Quiero detenerme en la enumeración de algunas de las razones que puedan explicar este desconocimiento, y al mismo tiempo indicar

\footnotetext{
${ }^{1}$ Con el título de «Relaciones entre teoría literaria y hermenéutica bíblica» este trabajo fue presentado como ponencia en el Seminario Internacional organizado por el Comité de Teoría Literaria de la Asociación Internacional de Literatura Comparada, en Santiago de Compostela, el 4 de julio de 1998. Es, a su vez, un resumen de la ponencia presentada en el V Simposio Bíblico Español, La Biblia en el Arte y en la Literatura, Pamplona, 17 de septiembre de 1997, con el título de «Teoría literaria y hermenéutica bíblica». La versión amplia aparecerá en las Actas del mencionado simposio.
} 
algo, de forma provisional y un tanto impresionista, sobre la utilidad de una consideración más atenta a las investigaciones del otro campo.

Una primera impresión, referida a nuestro siglo, es que los estudios bíblicos se han aprovechado más de los estudios literarios que éstos de aquéllos. En el tratamiento de cuestiones generales de teoría literaria en que hubiera sido muy útil fijarse en lo que se hace en el estudio de la Biblia, esto no ha sido así. Es chocante, por ejemplo, el que en obras generales, como las de William Ray (1984) sobre el significado literario o K. M. Newton (1990) sobre la interpretación del texto, no haya prácticamente ningún eco de lo que se hace en hermenéutica bíblica.

Esto se entiende si tenemos en cuenta que en la teoría literaria del siglo XX ha habido, en general, una despreocupación por la hermenéutica como conjunto de problemas referidos a la teoría de la interpretación sobre los que hubiera que reflexionar de forma independiente.

Otra razón fundamental se refiere a la duda sobre la naturaleza pragmática del texto bíblico. ¿Es literatura la Biblia? Si partimos de los términos en que Gérard Genette (1991) plantea la cuestión de la definición de la literatura, no parece que haya dudas respecto de la naturaleza estética y literaria del lenguaje bíblico, es decir, de su dicción. Ahí están los imprescindibles estudios de poética bíblica de Luis Alonso Schökel para demostrarlo. Más problemático es decidir si se trata de textos fundamentalmente ficticios; cualidad que los convertiría, por su misma constitución, en literarios. Pues la ficción es propiedad constitutiva de la literatura. Aunque el mismo Genette nos enseña, con el ejemplo de Northrop Frye, que un texto como la Biblia puede ser recibido al mismo tiempo como mito - -es decir, como no verdad, y entonces es condicionalmente ficticio, literario - y como verdad (Genette, 1991: 31-35). Pero el de Northrop Frye es sin duda un caso único de crítico literario estudioso de la Biblia.

Resumiendo y simplificando mucho, diríamos que la teoría literaria del siglo XX se ha despreocupado, en general, de la hermenéutica, y que las dudas acerca de la naturaleza literaria del texto bíblico han apartado del grupo de intereses de la teoría literaria todo lo que se decía sobre la Biblia: se trata de estudios religiosos, porque la Biblia no es literatura.

Sin embargo, parece conveniente un cambio de situación. Creo que la razón fundamental para que hermenéutica bíblica y hermenéutica literaria se sientan hermanadas está en el origen común de su problemática: un texto fijo, distante, separado de su autor, o del momento de 
su producción, espacial y temporalmente. Es oportuno recordar el mito platónico de la invención de la escritura al final del Fedro, donde se concluye que el texto escrito ni es firme, ni es claro; es mudo, en cuanto que no responde a las preguntas concretas; el texto rueda por doquier, tanto entre sabios como entre ignorantes; el texto, si es maltratado, necesita la ayuda del padre, autor, porque él no sabe defenderse (Fedro, 275 d-e).

En el origen del texto está, pues, una separación, una distancia en la que no tienen por menos de reconocer la constitución de los problemas que intentan resolver con su quehacer tanto exegetas bíblicos como críticos literarios.

En principio, pues, no hay razones para que la teoría literaria no atienda, al pensar sobre las cuestiones de la interpretación, a ese vasto mundo de la exégesis bíblica. Sobre todo cuando uno conoce manifestaciones explícitas acerca de la pluralidad de métodos empleados por el exegeta bíblico, que aleja de la tentación de identificar la interpretación de la Sagrada Escritura con un método específico exclusivamente. Es lo que podemos leer en el documento de la Pontificia Comisión Bíblica (1993), cuando trata de las dimensiones características de la interpretación católica, que «no procura distinguirse por un método científico particular». Por eso no les falta razón a los profesores que redactaron el texto del documento al decir que de esta manera, utilizando «todos los métodos y acercamientos científicos que permiten captar mejor el sentido de los textos», la exégesis católica contribuye «activamente al desarrollo de los métodos y al progreso de la investigación» (1993: 79). Y, sin embargo, en el campo de los estudios literarios no se atiende como se debería a los progresos de la exégesis bíblica.

A pesar de las dificultades para tratar de la misma manera un texto religioso y un texto literario, ha habido en nuestra historia cultural numerosos puntos de encuentro. La convivencia pacífica de teoría literaria y hermenéutica bíblica en San Clemente de Alejandría, por ejemplo, es un modelo de algo que, con distintos matices, perdurará mientras dure el clasicismo, hasta los tiempos modernos. No se han ignorado siempre, pues, hermenéutica bíblica y teoría literaria. Como tampoco ha faltado una tradición de estudio de la Biblia como obra literaria; tradición que ha sido historiada por Luis Alonso Schökel (1987: 229-256), con nombres como los de Casiodoro, San Isidoro de Sevilla o Beda el Venerable. Tradición en la que hay que incluir también a nuestro Benito Arias Montano y su Tractatus de figuris rhetori- 
cis cum exemplis ex sacra scriptura petitis, compuesto hacia 1585, y que ha merecido una reciente edición y traducción, con un estudio que lo sitúa en la historia de la poética bíblica.

Desde la teoría literaria de épocas pasadas no es raro tampoco el encuentro con la hermenéutica bíblica. La historia de tales contactos está por escribir, aunque no faltan materiales para la misma. Del tipo de noticias que habría que usar, ya ofrecí una muestra en mi trabajo sobre los Orígenes del discurso crítico (Domínguez Caparrós, 1993: 200216). A lo allí dicho sobre Dante, Petrarca o Boccaccio, principalmente, puedo añadir ahora algún otro ejemplo con el fin de ilustrar un poco qué tipo de contactos se han dado entre crítica literaria y hermenéutica bíblica. En este sentido, cabe recordar cómo Enrique de Villena (1384-1434), quien había comentado, en Los doce trabajos de Hércules, las historias mitológicas siguiendo el esquema de la narración de la fábula con su sentido alegórico, su interpretación histórica o racionalista y su aplicación moral, nos ofrece, en su Tratado de la lepra (1994: 119), una curiosa mención de Nicolás de Lira, transmisor del famoso dístico de Agustín de Dacia:

«Siempre oí a valientes maestros devían ser las declaraçiones e entendimientos de las palabras de la ley conservantes el mesmo testo e non desviantes e menos contradizientes del e al entendimiento literal. E así paresçe lo tenga Nicolao de Lira en el principio de su declaraçión sobre el testo bíblico, tanto que reprehende a sant Agustín, reverençia propuesta, porque dixo Super Genes. que Dios fiziera todas las cosas en un instante, derrogando que puso la criaçión en e por departidos días».

Es oportuno recordar igualmente cómo Juan de Mena (1411-1456), en los comentarios a su Coronación del Marqués de Santillana, explica en el preámbulo cuarto el alcance de su glosa, donde, entre otras cosas, «verán las vidas, nasçimientos, muertes e linajes de aquellos, e leído por tres sesos en los lugares que conviene». Y, efectivamente, el esquema de su exposición se ajusta a los siguientes sentidos: el que Juan de Mena llama ficción, que tiene que ver con el sentido literal, la fábula narrada; la que llama estoria e verdad, que tiene que ver con una interpretación racionalista de tipo evemerista, es decir, los hechos realmente ocurridos que pueden haber servido de base para la alegoría de la fábula literaria, es decir, a la ficción; en tercer lugar, está la moralidad y aplicación, que trata de la explicación de su sentido moral (Mena, 1989: 105-208).

Un libro como el de Pier Cesare Bori, L'interpretazione infinita (1987), ofrece un ejemplo del tipo de relaciones que habría que esta- 
blecer entre hermenéutica bíblica y teoría literaria en la historia de esta disciplina. En su recorrido desde la Edad Media hasta el Romanticismo llega a conclusiones tan interesantes como cuando observa que inspiración, sentido infinito, letra y espíritu son atributos cada vez más aplicados a cualquier texto, aunque en su origen eran de carácter sagrado, lo que indica, a su vez, cómo en el origen todo texto era atraído a la esfera sagrada.

En esta nueva historia de la teoría literaria ocuparía un lugar importante, por ejemplo, el pensamiento de Miguel de Unamuno respecto de la interpretación del Quijote, donde la referencia explícita a la Biblia no hace más que corroborar el hecho de estar compartiendo con la hermenéutica bíblica una serie de problemas, cuestiones y actitudes. En efecto, en el artículo publicado en 1905 con el título de «Sobre la lectura e interpretación del Quijote», Unamuno propone leer la obra de Cervantes con la misma actitud con la que se lee la Biblia, sin censurar el «sentido simbólico o tropológico».

La poética del siglo XX tenía unos objetivos bien precisos: la descripción de la literariedad. Descripción absolutamente necesaria hasta el punto de que Paul de Man (1979: 18-19) puede hablar de «higiene semiológica preventiva» cuando trata de los resultados tan fructíferos como irreversibles de la poética en el cultivo que de ella se hace en la semiología francesa.

No me detengo a hablar de la imposibilidad de una interpretación inmanente, señalada por Tzvetan Todorov (1973), lo que le lleva a establecer unas relaciones de complementariedad e incompatibilidad entre interpretación y poética.

Recurro a Roland Barthes para entender lo alejados que están de la hermenéutica los objetivos de un análisis textual que nos lleva directamente a las modernas teorías de la deconstrucción del significado del texto. En el artículo famosísimo de 1968 en que Barthes proclama la muerte del autor - uno de los grandes tópicos de la teoría literaria más moderna - se anuncia igualmente la muerte de la crítica, en unos términos que nos pueden aclarar perfectamente las posiciones y el poco espacio que queda para la hermenéutica en los programas formalistas de teoría literaria:

«Una vez alejado el Autor, la pretensión de "descifrar" un texto se hace totalmente inútil. Dar un Autor a un texto, es imponer a este texto un seguro, es proveerlo con un significado último, es cerrar la escritura. Esta concepción conviene muy bien a la crítica, que entonces quiere darse como 


\begin{abstract}
tarea importante la de descubrir al Autor (o sus hipóstasis: la sociedad, la historia, la psique, la libertad) debajo de la obra: encontrado el Autor, el texto está "explicado", el crítico ha vencido; no hay, pues, nada de asombroso en que, históricamente, el reino del Autor haya sido también el de la Crítica, pero tampoco en que la crítica (aunque sea nueva) sea hoy desestabilizada al mismo tiempo que el Autor. En la escritura múltiple, en efecto, todo está por aclarar, pero nada por descifrar; la estructura puede ser seguida, "corrida" (como se dice de un punto de media que se va) en todas sus aceleraciones y en todos sus planos, pero no tiene fondo; el espacio de la escritura es un espacio a recorrer, no a horadar; la escritura propone sin cesar sentido pero siempre es para evaporarlo: procede a una dispensa sistemática del sentido. Por eso mismo, la literatura (sería mejor decir en adelante la escritura), rechazando asignar al texto (y al mundo como texto) un "secreto", es decir, un sentido último, libera una actividad que se podría llamar contra-teológica, propiamente revolucionaria, porque rechazar parar el sentido, es en definitiva rechazar a Dios y sus hipóstasis, la razón, la ciencia, la ley» (Barthes, 1984: 65-66).
\end{abstract}

Pues bien, aun en este clima no han faltado las miradas de una atención parcial a aspectos relacionados con la hermenéutica bíblica o con las teorías y cuestiones que se suscitan en su entorno. Así, cuando la semiótica ha indagado sobre unos orígenes, se ha encontrado, por ejemplo, con la teoría medieval. Umberto Eco, con su temprano estudio de la estética de Santo Tomás (1988), dio muestras de interés por una parcela de los estudios medievales que no abandonará a lo largo de todo su trabajo (Eco, 1985: 231-259; 1987: cap. 6).

Tzvetan Todorov, en sus trabajos sobre teorías del símbolo y sobre simbolismo e interpretación, mira frecuentemente al conjunto de problemas del ámbito de la hermenéutica bíblica.

Que hay materiales para escribir una historia de la atracción que los teóricos de la literatura han sentido por la Biblia, lo demuestra el documentado trabajo de Robert Detweiler y Vernon K. Robbins sobre crítica literaria y hermenéutica bíblica del siglo XX. El campo de las relaciones está cambiando; estas relaciones, según los autores, se establecían antes en tres campos: 1) en el de los estudiosos de la Biblia que, siguiendo en la crítica histórica, importaban métodos de los estudios literarios (estructuralistas, narratología, recepción); 2) en el de los críticos literarios que leían la Biblia según sus métodos y relacionándola con los demás textos literarios; 3) en el de los críticos literarios que leían otros textos fijándose en la influencia de la Biblia en la composición y comprensión de dichos textos. Lo que falta en el panorama trazado por Detweiler y Robbins es la aplicación de teorías producidas en el campo de la hermenéutica bíblica - del tipo de la de los cuatro sentidos, o la interpretación infinita, historiada por P. C. Bori- al 
campo de los estudios literarios. Con todo, en el trabajo de estos autores pueden verse algunos detalles y datos muy interesantes sobre las relaciones entre interpretación bíblica y literaria en el siglo XX en Alemania, Francia, Inglaterra y Norteamérica. Por lo que respecta a la teoría literaria, allí se encontrarán noticias acerca de las relaciones del New Criticism americano de los años 40 y 50 con la Biblia, lo mismo que de las del estructuralismo; la interesante labor de la teórica de la literatura Mieke Bal, en que combina poética de la narración, interpretación bíblica y teoría feminista, o las aplicaciones a la Biblia de postestructuralistas judíos como Geoffrey Hartman o Harold Bloom. Me ha llamado la atención que los autores sostengan que el estructuralismo de Barthes «lleva de hecho a los primeros intercambios significantes de críticos literarios y bíblicos por el que los estudiosos de la literatura interpretan textos bíblicos y estudiosos de la Biblia leyeron textos literarios con perspicacia» (Detweiler y Robbins, 1991: 257. [Traducción mía]).

En efecto, Roland Barthes, lo mismo que analiza un texto de E. A. Poe, de Balzac o de Julio Verne, aplica a textos bíblicos su vistosa forma de comentario. Es lo que hace en el análisis estructural del relato de los capítulos 10 y 11 de los Hechos de los Apóstoles, y en el análisis textual del episodio de la lucha de Jacob con el ángel (Génesis, 32) (Barthes, 1985: 281-322).

Desborda el límite de mis posibilidades el comentar en este momento muchos más detalles de la presencia del mundo bíblico en el quehacer de algunos de los más importantes teóricos. Con todo, me resisto a dejar de citar, aunque no sea más que en una enumeración, los nombres de Julia Kristeva (1982) y la relación que establece entre la Biblia y el psicoanálisis; Jacques Derrida y la historia de la Torre de Babel como alegoría de la deconstrucción; o la importancia que se asigna al significante tanto en la interpretación rabínica como en la deconstruccionista; Harold Bloom y su relación con la Cábala (Hart, 1991); o J. Hillis Miller (1993) y su propuesta de análisis de la historia de Rut como alegoría del viaje de la teoría desde un emplazamiento cultural a otro, desde una lengua a otra.

Casos bien distintos son los del canadiense Northrop Frye (19121991) y el norteamericano Fredric R. Jameson (1934). Deben ser destacados porque ya sí se trata de un contacto directo y decisivo entre hermenéutica bíblica y teoría literaria. En el caso de Northrop Frye, para proponer una teoría inmanentista de la literatura en la que tiene un lugar importante la propuesta de los planos de sentido de la herme- 
néutica bíblica. En el de Fredric R. Jameson por trasplantar la actitud de la hermenéutica bíblica a una propuesta de interpretación en la que el marxismo se convierte en el horizonte anagógico de la literatura, es decir, el marco en el que la literatura adquiere su sentido histórico y social. No nos puede extrañar que Fredric Jameson se haya referido a la obra de Frye, Anatomía de la crítica, como «una virtual reinvención contemporánea de la cuádruple hermenéutica asociada a la tradición teológica», al tiempo que destaca el aspecto social, de representación colectiva, que hay en sus propuestas. Y, si su valoración del trabajo de Frye es muy positiva, esto se debe, piensa Jameson (1981: 56), a que

\begin{abstract}
«para toda reevaluación contemporánea del problema de la interpretación, el intercambio de energías más vital tiene lugar inevitablemente entre los dos polos de lo psicoanalítico y lo teológico, entre la rica práctica concreta de interpretación contenida en los textos freudianos y dramatizada en el genio diagnóstico del propio Freud, y la reflexión teórica milenaria sobre los problemas y la dinámica de la interpretación, el comentario, la alegoría y los múltiples significados, que, organizada primariamente en torno al texto central de la Biblia, queda preservada en la tradición religiosa».
\end{abstract}

Pero Northrop Frye no se limita a la teoría, sino que en su libro de 1982, El gran código, nos da el mejor ejemplo de estudio de la Biblia en relación con la literatura occidental. Desde una actitud comparatista, el libro de Frye tiene un interés máximo para el teórico literario y para el estudioso de la Biblia. Su lectura, para quien esté algo familiarizado con la hermenéutica bíblica y con la teoría de la literatura, es una fuente de placer por el gusto, el sabor y el disfrute en una cultura próxima.

Por su parte, Jameson hace, desde una perspectiva política, la más interesante propuesta de hermenéutica marxista de la literatura, en cuyos detalles no puedo entretenerme ahora.

Jameson, en la teoría literaria moderna, se alinea claramente en posiciones interpretativas, hermenéuticas, pero inspiradas en el marxismo, lo que no le impide reconocerse en la tradición de otras orientaciones hermenéuticas y principalmente la teológica, en la que el texto «expresa» un sentido de la historia.

A Jameson le fascina «esa impresionante y elaborada hermenéutica que es la patrística y el sistema medieval de los cuatro niveles de la escritura» (1981: 24) por lo bien que ilustra la estructura del relato maestro encargado de la transformación ideológica de los textos sagra- 
dos. En este sistema, el sentido anagógico propone una lectura política (desde un «significado» colectivo de la historia); el moral, una lectura psicológica (sujeto individual); el alegórico, clave alegórica o código interpretativo (abre el texto a posteriores invasiones ideológicas, porque la alegoría concreta el poder simbólico, plurisignificativo del texto en todo momento); el literal, referente histórico o textual (Jameson, 1981: 25-26).

Su propuesta, desde la perspectiva del marxismo, supone que éste proporciona las precondiciones necesarias para una comprensión literaria adecuada, especialmente la del enriquecimiento semántico de los datos y materiales inertes de un texto particular. El marxismo «enriquece» semánticamente el texto literario.

No hay duda de que el pensamiento de Northrop Frye y el de Fredric Jameson demuestran un buen conocimiento de la hermenéutica bíblica, y sus propuestas entrarían perfectamente en un programa de cooperación entre ésta y la teoría literaria.

Sin ser especialista en exégesis bíblica, enumero solamente aquellas orientaciones que se sienten como activas en la moderna crítica literaria, y que se emplean en la interpretación de la Biblia. Prescindiendo de los métodos propios de la historia de la literatura, hay que destacar la estilística, tan diestramente utilizada por Luis Alonso Schökel en la construcción de una teoría de la lengua literaria bíblica. A la vista del resultado de esta labor, llama poderosamente la atención que entre los estudios de estilística a los que se suele acudir en nuestras universidades no se cite, por ejemplo, su trabajo sobre poética hebrea, además de los muchos análisis de textos concretos. El estudiante de literatura, aparte de disfrutar con los modelos de agudeza interpretativa y buen hacer analítico, ensancharía el horizonte de comprensión de la poética propia con las magníficas lecciones de comparatismo que allí verá. Pues no es fácil encontrar, en nuestra filología, un caso igual de poética comparada del español con otra lengua. La semiótica, tal como se ensaya tempranamente, es decir, con métodos todavía no muy desarrollados, está representada en la colección de trabajos editados por C. Chabrol y L. Marin (1971). Aquí puede leerse el estudio de Edmund R. Leach sobre «El Génesis como mito», inspirado en la concepción estructural del mito. O la semiótica como se presenta ya con todos los refinamientos de la inspiración greimasiana en las investigaciones del Grupo de Entrevernes (1977, 1979), que, lo mismo que su pariente literaria, no trata de dar una interpretación, sino de estudiar las condiciones de la pluralidad de sentidos de los textos. Se llega incluso a 
ensayos tan modernos como los de la deconstrucción postestructuralista (Hart, 1991: 310-327). Una revista bien conocida del especialista en estudios bíblicos como es Semeia parece acoger en sus páginas lo más actual de la teoría literaria aplicada a la Biblia (Detweiler y Robbins, 1991: 258). Llama la atención también la pujanza que, lo mismo que en los estudios literarios, tiene la interpretación feminista de la Biblia (Russell, 1995).

Una más completa presentación, sistemática y crítica, de todos los métodos y acercamientos empleados en la interpretación bíblica puede leerse en el documento de la Pontificia Comisión Bíblica. El teórico de la literatura se sorprende de la riqueza de los mismos y no puede nada más que admirar la serenidad y precisión con que se atina a ponderar las ventajas e inconvenientes de cada uno de ellos, desde el método histórico-crítico hasta la lectura fundamentalista, pasando por los nuevos métodos de análisis literario (retórico, semiótico), los acercamientos basados en la tradición (canónico, tradiciones judías de interpretación, historia de los efectos del texto), los acercamientos por las ciencias humanas (sociológico, antropológico cultural, psicológico y psicoanalítico) y acercamiento contextual (liberacionista, feminista).

La ventaja de aplicar los métodos literarios a textos que han sido objeto de tan larga tradición interpretativa como los bíblicos es que se tiene una amplia muestra con la que contrastar y valorar el interés de los resultados. Por eso, la estética de la recepción, por ejemplo, avanzará mucho trabajando con textos de cuyas lecturas en distintas épocas hay muchos testimonios y que han sido además leídos por muy diferentes clases de lectores en lugares y lenguas muy distintos. Esto supone una gran ventaja sobre cualquier otro texto de una literatura particular. El patrimonio cultural de la Biblia es incomparablemente más rico que ningún otro.

Es sorprendente la ausencia prácticamente total de este tipo de trabajos en los programas de estudios literarios, que se limitan a la literatura nacional. Quizá sea por la vía de la teoría de la literatura por donde puedan alcanzar un justo lugar en la educación literaria de nuestras universidades. Si digo esto, es porque en el campo de la teoría literaria las cosas empezaron a cambiar hace ya algún tiempo.

Como todos sabemos, hace años que se proclamó la crisis de la literariedad, en el sentido de que se desistió del empeño de encontrar unas propiedades formales del texto que automáticamente lo convirtieran en 
literario. Se amplía el campo de investigación y las orientaciones de las mismas, que no es necesario detallar aquí.

Pues bien, justo en este ambiente se crea un espacio para una atención más interesada a las cuestiones de la interpretación. La situación cambiante ya había sido detectada, entre otros muchos, por Paul de Man, cuando al principio de Alegorías de la lectura (1979: 15) dice:

«A juzgar por varias publicaciones recientes, el espíritu de los tiempos no sopla en la dirección de la crítica intrínseca y formalista. Es muy posible que pronto dejemos de oír hablar de la relevancia y, en cambio, oigamos mucho acerca de la referencia, acerca del "afuera" no verbal al que se refiere el lenguaje, por el cual es condicionado y sobre el cual actúa».

No faltan los datos que apuntan los cambios en esta dirección desde hace años, y cómo el lenguaje común a las humanidades hoy es el de la hermenéutica, así como un poco antes lo era el de la lingüística, según ha observado G. Vattimo. Una de las orientaciones críticas que de forma indiscutible se acepta que está en el principio de este cambio es la estética de la recepción, cuya fundación se puede datar en el discurso pronunciado por Hans Robert Jauss el 13 de abril de 1967 en la Universidad de Constanza con el título de «La historia literaria como desafío a la ciencia literaria», que va a ser el manifiesto de esta escuela. La insistencia de Hans Georg Gadamer en la naturaleza histórica de la interpretación es uno de los ingredientes esenciales de la nueva orientación crítica. No puede extrañar entonces el que Jauss (1990: 54) reconozca explícitamente en la interpretación de Homero y la Biblia uno de los orígenes de la estética de la recepción:

\begin{abstract}
«En la tradición europea, las prehistorias solo son verdaderamente respetables si pueden rastrear sus orígenes hasta Homero y la Biblia. Dejando aparte un momento la tardía aparición del concepto de receptio y mirando al problema hermenéutico que surgió mucho antes, la teoría de la recepción podría invocar estas dos fuentes. Pues el problema de la recepción fue planteado primero en la interpretación de Homero y después nuevamente en la exégesis de la Biblia, cuando la distancia del texto original era tan grande que la poesía de Homero y las revelaciones contenidas en las Sagradas Escrituras dejaron de ser inmediatamente comprensibles; de hecho, cuando en los tiempos modernos su significado canónico se ha hecho oscuro, si no desagradable u ofensivo».
\end{abstract}

Es lógico que N. Frye (1982: 19) observe cómo muchos puntos en la teoría crítica de hoy se originaron en el estudio hermenéutico de la Biblia. 
En conclusión, no hay dudas de que se ha creado un espacio en la teoría literaria actual para que la consideración de muchos de los problemas que preocupan en exégesis bíblica tenga interés porque se trata de problemas similares a los que preocupan en los estudios literarios, como no podía por menos de ser.

Quiero terminar con una esquemática y desordenada relación de algunas de estas cuestiones que al mismo tiempo puede ser un prólogo del programa de colaboración entre hermenéutica bíblica y teoría literaria.

El problema hermenéutico fundamental, que reside en la historicidad de la interpretación, con el consiguiente resultado de que ésta se convierte en una tarea infinita, es algo bien asumido en la hermenéutica bíblica y que debería ser igualmente asimilado por los estudiosos de la literatura. R. Barthes o Umberto Eco han tratado la cuestión, como sabemos. Un teórico de la literatura tiene que interesarse forzosamente por un trabajo como el de David Tracy (1987) sobre pluralidad y ambigüedad en el texto religioso.

En este ambiente de preconización de la riqueza significativa del texto literario y religioso, porque perduran en la historia, es especialmente valiosa una consideración como la de Jorge Luis Borges en los siguientes términos, con que empieza una conferencia sobre «La poesía»:

\begin{abstract}
«El panteísta irlandés Escoto Erígena dijo que la Sagrada Escritura encierra un número infinito de sentidos y la comparó con el plumaje tornasolado del pavo real. Siglos después un cabalista español dijo que Dios hizo la Escritura para cada uno de los hombres de Israel y por consiguiente hay tantas Biblias como lectores de la Biblia. Lo cual puede admitirse si pensamos que es autor de la Biblia y del destino de cada uno de sus lectores. Cabe pensar que estas dos sentencias, la del plumaje tornasolado del pavo real de Escoto Erígena, y la de tantas Escrituras como lectores del cabalista español, son dos pruebas, de la imaginación celta la primera y de la imaginación oriental la segunda. Pero me atrevo a decir que son exactas, no sólo en lo referente a la Escritura sino en lo referente a cualquier libro digno de ser leído» (Borges, 1993: 101).
\end{abstract}

Esta perdurabilidad de la potencia significativa de un texto está, sin duda, relacionada con la calidad de clásico, concepto clave en la literatura si se quiere justificar la existencia de un canon en el que se integren los grandes textos del pasado. La actualidad de la discusión es enorme, $y$, por supuesto, no faltan las referencias a lo que ocurre con el canon bíblico (Bloom, 1994; Pozuelo, 1995). El ejemplo de la 
Biblia, que siempre tiene algo que decir, como muy bien ha señalado Luis Alonso Schökel (1986: 46; 1997), es el modelo de todo clásico literario. Es el modelo que Unamuno (1905) proponía para el Quijote.

Las preocupaciones y problemas relativos a la inculturación tienen que ser una mina de datos para el comparatista literario, que puede aprender de la forma en que todos los valores universales establecidos por Dios se encuentran en las distintas culturas, o cómo la interpretación se lleva a cabo en directa relación con los modos de sentir de la nueva cultura hasta formar una cultura local cristiana (Pontificia Comisión Bíblica, 1993: 110-111).

La forma en que interviene la comunidad de los creyentes en el establecimiento de los límites del significado de las Escrituras debe despertar la curiosidad de quienes al tratar del sentido de la obra literaria analizan el papel que en la constitución de dicho sentido tienen las comunidades interpretativas, según hace Stanley Fish (1980).

Por último, una cuestión como la del sentido de la literatura en una sociedad o en un devenir histórico está estrechamente relacionada, según hemos insinuado antes, con el sentido anagógico del esquema medieval. Autores como Barthes no son ajenos al sentido de una responsabilidad histórica de las formas, a una esencia histórica de la literatura. Así es como, por ejemplo, este autor puede ver como programa histórico de la literatura contemporánea de los últimos cien años el ataque al sujeto de la enunciación, al imperio del sujeto psicológico del autor. No es necesario insistir en el pensamiento de $\mathrm{F}$. Jameson; baste recordar algo que está muy claro en toda interpretación marxista y que Lenin exponía con mucha claridad cuando, para explicar que las intenciones objetivas de los escritores no siempre corresponden a la significación objetiva de sus escritos, decía:

«Desde el momento en que lo ha escrito usted, entra en las masas, y su significado se determina no sólo según sus buenos deseos, sino según las relaciones de las fuerzas sociales, las relaciones objetivas entre las clases» (Lenin, 1957: 106).

Hay, pues, una fuerza social que dota de sentido al texto dentro de una filosofía de la historia.

Como vemos, es muy sugerente lo que la teoría de la literatura, en esta época de predominio de la hermenéutica, puede encontrar en el 
campo de la exégesis bíblica. Ha llegado el momento de cambiar la dirección de la curiosidad; y si la exégesis bíblica se ha sentido atraída por los estudios formalistas en un momento, y los ha integrado en su quehacer, ahora es la teoría literaria la que tiene que acercarse para aprender de la hermenéutica bíblica.

Sea lo que haya de ser de una colaboración entre teoría literaria y hermenéutica bíblica, no hay duda de que la lectura obligatoria en los cursos de crítica literaria de un libro como los Apuntes de hermenéuti$c a$, de Luis Alonso Schökel y José María Bravo, responderá a preguntas que subyacen en muchos de los problemas del estudiante de literatura, aunque no le hayan ayudado a planteárselas, y que en todo caso es necesario que se las plantee. Del beneficio de esta lectura estoy convencido. Es un ejemplo de por dónde empezar.

\section{Referencias bibliográficas}

ALONSO SCHÖKEL, L. (1986). Hermenéutica de la palabra. I. Hermenéutica bíblica. Madrid: Ediciones Cristiandad.

- (1987). Hermenéutica de la palabra. II. Interpretación literaria de textos bíblicos. Madrid: Ediciones Cristiandad.

Alonso SchöKEL, L. y Bravo, J. M. (1994). Apuntes de hermenéutica. Madrid: Trotta.

ARIAS MONTANO, B. (1995). Tractatus de figuris rhetoricis cum exemplis ex sacra scriptura petitis. Estudio, edición, traducción y notas de Luis Gómez Canseco y Miguel A. Márquez Guerrero. Huelva: Universidad, Ediciones Clásicas.

BARTHES, R. (1984). Le bruissement de la langue. París: Seuil.

- (1985). La aventura semiológica. [Trad. Ramón Alcalde.] Barcelona: Paidós, 1990.

Bloom, H. (1979). La cábala y la crítica. [Trad. anónima.] Caracas: Monte Ávila, $1992^{2}$.

- (1994). El canon occidental. La escuela y los libros de todas las épocas. [Trad. Damián Alou.] Barcelona: Anagrama, 1995.

BORGES, J. L. (1993). Siete noches. Madrid: F.C.E.

BORI, P. C. (1987). L'interpretazione infinita. Bologna: Il Mulino.

ChABROL, C. y MARIN, L. (eds.) (1991). Semiótica narrativa: relatos bíblicos. [Trad. M. Gómez Molleda.] Madrid: Narcea, 1975.

De MAN, P. (1979). Alegorias de la lectura. [Trad. de Enrique Lynch.] Barcelona: Lumen, 1990.

DetweIleR, R.; Robbins, V. K. (1991). «From New Criticism to Poststructuralism: Twentieth-Century Hermeneutics». En Reading the Text. 
Biblical Criticism and Literary Theory, S. Prickett (ed.), 225- 280. London: Basil Blackwell.

Domínguez CAPARRós, J. (1993). Orígenes del discurso crítico. Teorías antiguas y medievales sobre la interpretación. Madrid: Gredos.

ECo, U. (1985). De los espejos y otros ensayos. [Trad. Cárdenas Moyano.] Barcelona: Lumen, 1988.

- (1987). Arte y belleza en la estética medieval. [Trad. de Helena Lozano Miralles.] Barcelona: Lumen, 1997.

- (1988). The Aesthetics of Thomas Aquinae. [Trad. Hugh Bredin.] London: Radius.

FisH, S. (1980). Is there a text in this class? The authority of interpretive communities. Cambridge: Harvard University Press.

FrYE, N. (1957). Anatomía de la crítica. [Trad. Edison Simons.] Caracas: Monte Ávila, 1977.

- (1982). El gran código. Una lectura mitológica y literaria de la Biblia. [Trad. Elizabeth Casals.] Barcelona: Gedisa, 1988.

GenetTe, G. (1991). Fiction et diction. Paris: Seuil.

GRUPO DE ENTREVERNES. (1977). Signos y parábolas. Semiótica y texto evangélico. [Trad. Iván Almeida.] Madrid: Ediciones Cristiandad, 1979.

- (1979). Análisis semiótico de los textos. Introducción. Teoría. Práctica. [Trad. Iván Almeida.] Madrid: Ediciones Cristiandad, 1982.

HART, K. (1991). «The poetics of the negative». En Reading the text. Biblical criticism and literary theory, S. Prickett (ed.), 281-340. London: Basil Blackwell.

JAMESON, F. (1981). Documentos de cultura, documentos de barbarie. La narrativa como acto socialmente simbólico. [Trad. Tomás Segovia.] Madrid: Visor, 1989.

JAUSS, H. R. (1990). «The theory of reception: a retrospective of its unrecognized prehistory». En Literary Theory Today, Peter Collier y Helga GeyerRyan (eds.), 53-73. Oxford: Polity Press, 1992.

KRISTEVA, J. (1982). «Lire la Bible». Esprit 9, 143-152.

LENIN, V. I. (1957). Escritos sobre la literatura y el arte. Selección y prólogo de Jean Fréville. [Trad. Jaume Fuster y María-Antònia Oliver.] Barcelona: Península, 1975.

MENA, J. de. (1989). Obras completas. Edición, introducción y notas de Miguel Á. Pérez Priego. Barcelona: Planeta.

MilleR, J. H. (1993). Cruce de fronteras: traduciendo teoría. [Trad. y notas de Mabel Richart.] Valencia: Amós Belinchón.

Newton, K. M. (1990). Interpreting the text. A critical introduction to the theory and practice of literary interpretation. New York and London: Harvester Wheatsheaf.

Pontificia Comisión Bíblica (1993). La interpretación de la Biblia en la Iglesia. Valencia: Arzobispado de Valencia.

PozUelo YvANCOS, J. M. (1995). El canon en la teoría literaria contemporánea. Valencia: Episteme. 
RAY, W. (1984). Literary meaning. From phenomenology to deconstruction. Oxford: Basil Blackwell, 1989.

Russell, L. M. (ed.) (1995). Interpretación feminista de la Biblia. [Trad. Manuel Alfonso Díez Aragón.] Bilbao: Desclée De Brouwer.

Todorov, T. (1973). Poétique. París: Seuil.

- (1977). Théories du symbole. París: Seuil.

- (1978). Symbolisme et interprétation. París: Seuil.

TraCY, D. (1987). Pluralidad y ambigüedad. Hermenéutica, religión, esperanza. [Trad. María Tabuyo y Agustín López.] Madrid: Trotta, 1997.

UNAMUNo, M. de (1905). «Sobre la lectura e interpretación del Quijote». En La España Moderna 17, 196, 5-22.

Villena, E. de. (1994). Obras Completas, I. [Ed. Pedro M. Cátedra.] Madrid: Turner. 